\title{
Dilbilimin Alt Alanları Ve Ekler
}

\section{Sub-Branches Of Linguistics And Affixes}

\begin{abstract}
Hasan KARACA*
Özet

Eklemeli bir dil olan Türkçenin işletimi, bu yapısı gereği daha çok ek sayesinde olmaktadır. Türkçede, çoğu birden fazla kullanım çeşitliliğine sahip iki yüzden fazla ek bulunmaktadır. Bunların sınıflandırılmasına dair yapım eki, çekim eki ayrımının yüzeysel ve yetersiz bir sınıflandırma olduğu genel kabul görmüştür. Bu çerçevede, eklerin sınıflandırılmasına dair yapılan çalışmalarda bariz bir çeşitlilik göze çarpmaktadır. Bu çeşitliliğin sebebini eklerin esas alınıp öncelenen özelliklerindeki farklılıklarda aramak gerekir. Çünkü dilbilimin alt dallarına göre eklerin kullanım rolü ve işlevi değişmektedir. Ses bilim, biçim bilim söz dizimi, sözlükbilim ve bürünbilim pencerelerinden eklerin işlev, görev ve rolleri birbirinden farklı görünümlere sahiptir. Eklerin dilbilimin farklı alanlarındaki bu kullanım özellik ve görünümleri, ittifak e dilmiş doğru bir sınıflandırmaya ışık tutacaktır.

Anahtar kelimeler: yapım eki, çekim eki, ses bilim, biçim bilim, söz dizimi, sözlükbilim
\end{abstract}

\begin{abstract}
The execution of Turkish which is an agglutinating language is achieved mostly through affixes. In Turkish there are more than two hundred affixes most of which have more than a single usage variation. The distinction between derivational and inflectional affixes relating to the classification of these affixes is accepted rather as a superficial and insufficient classification. In this frame an apparent diversity attracts attention about works concerning the classification of affixes. The reason of this diversity should be searched in the differences within the features of affixes which have been based on and given a certain priority. Because role and function of affixes with regard to their usage, change according to sub-branches of linguistics. From the points of phonetics, morphology, syntax, lexicography and prosody functions, tasks and roles of affixes have different appearances. These usage features and views of affixes in different fields of linguistics are to pave the way for an agreed and accurate classification.
\end{abstract} Key words: derivational affix, inflection suffix, phonetics, morphology, syntax, lexicography

\section{Giriş}

Eklerin sınıflandırmasına dair yapılan çalışmalarda bariz bir çeşitlilik göze çarpmaktadır. Bu çeşitliliğin sebebini eklerin esas alınıp öncelenen özelliklerindeki farklılıklarda aramak gerekir. Bu açıdan bakıldığında, aslında bütün sınıflandırmalar doğrudur, ancak biri diğerine göre eksiklikler taşımaktadır, diyebiliriz. Eke dair yapı, işlev, görev gibi kullanımlar ya da ekin büründüğü farklı roller sınıflandırmalarda görüş ayrılıklarına yol açmıştır. Ses bilim, biçim bilim, söz dizimi, sözlükbilim hatta bürünbilim alanlarında eklerin üstlendiği rol başka başkadır. Dolayısıyla eklerin işlevlerine çizilen sınırların muğlaklığı, bir özelliği önemseme ve önceleme tercihi gibi sebeplerden sinıflandırmalarda birbiriyle örtüşmeyen sonuçlar ortaya çıkmaktadır.

Yirminci yüzyıl başlarında Saussure ile başlayan ve onun "Dil bir sistemdir." (Başkan, 2003: 78) düsturundan hareketle dili bir mekanizma olarak ele alan yapısalcılık, dili ve dilbilimi bağımsız bir bilim dalı olarak ele alma çalışmalarına çağ atlatmıştır. Ancak, bu akımdan hareketle dile matematiksel bakan Kopenhag Okulu (Glosematikçiler) ile ses ve biçim çalışmalarına üstünlük tanıyan Amerikan Okulu'nun önemli temsilcilerinden Bloomfield ve ondan sonra gelmiş olan Bloch ve Harris anlam ve işlevi ölçülebilir olmadığı için dışlayan bir yaklaşım sergilemişlerdir (Başkan, 2003, s. 97). Bu da dili aşırı biçimci bir metotla incelemeye sevk etmiştir. Türkçenin eklerine dair genel ve biçimci sınıflandırmayı bu akımlardan bağımsız düşünmemek gerekir. Şekilci yaklaşım işlevden büsbütün ayrı değildir. Kaldı ki şekilciliğin

\footnotetext{
*Dr., Gaziantep Üniversitesi, Fen-Edebiyat Fakültesi, Türk Dili Bölümü, karaca@gantep.edu.tr
} 
matematiksel kesinliğini ve şematik keskinliğini elde etmeye çalışırken bile anlam ve işlev kriterleri işletilmektedir. Ek adlandırmalarını buna örnek verebiliriz.

Türkçede dilbilgisi çalışmalarının ekserisi, ek konusunu şekilci bir yaklaşımla ele almıştır. Eklerle ilgili işlev merkezli çalışmalar ise oldukça yeni ve sınırlı sayıdadır. $\mathrm{Bu}$ çalışmaların başlıcaları şunlardır: Delice (2000): "Türk Dilinde İşlevsel Ek Tasnifi Denemesi" bu makaleye dayanan yüksek lisans tezi Özel (2003): Türkçede Eklerin Tasnifi, doktora tezi Karaca (2013): Türkiye Türkçesinde Eklerin İşlevleri, Turan (2000): “Türkçenin Yapım ve Çekim Düzeninde Yer Alan Eklerin Sınıflandırılması Nasıl Olmalıdır?”, Gülsevin (2004): “Türkçede 'Sıra Dışı Ekler' ve Eklerin Tasnif-Tanımlanma Sorunu Üzerine”, Başdaş (2006): “Türkçede Üçüncü Grup (Ara) Ekler”. Bu konuda çalışmalar derinleşip arttıkça görüş birliğinin sağlandığı bir sınıflandırmanın ortaya çıkacağı inancındayız.

\section{Ses Bilim ve Ekler}

Anlam sağlayıcı dilbilgisel birim ve bağımlı biçimbirim olmaları dolayısıyla ekler, çoğu zaman seslerden oluşmuş parçalar olarak değerlendirilmiş, ses bilimin sınırlarında ele alınmıştır. Dilin birinci eklemlilik düzleminin ikinci eklemlilik düzlemine en yakın yanı eklerdir. Yapı olarak kullanım işlevi ortaya çıkarılmadığı sürece ses ve ek aynı olabilmektedir. Dilde kullanılan kimi ses birim, ek, hatta sözcük aynıdır. Yerine göre "o", sesbirim, zamir, sıfat veya ünlem olabilmektedir. Ayırıcı ve belirleyici olan, sistem içindeki görevidir.

Ses bilim penceresinden bakıldığında ekler, ekteki ses birimler ve bunların birleşme kuralları, ses olayları, fonemden morfeme geçiş, aynı ekin ayrı seslerle (-1Ar) karşılanması (alomorf) ve bunun sayısı bakımlarından kategorilere ayrılmaktadır.

\section{Biçim Bilim ve Ekler}

Eklerin asıl var oluş sahası sözcük bünyesidir. Morfolojik olarak sözcük için geçerli olan kural ve kriterler ekler için de geçerlidir. Sözcüklerin gösterdiği yapı, anlam ve işlev hususiyetlerini çoğu zaman ekler de göstermektedir. Ekler, dilin birincil dilbilgisi ulamları dediğimiz sözcüklere gelerek sayı, çokluk, durum, soru, şahıs, kip gibi ikincil dilbilgisi ulamlarını elde etmemizi sağlar (Vardar, 2002, s. 202). Bağımlı biçimbirimlerin yani eklerin çoğu, tıpk1 sözcükler gibi birden fazla işleve sahiptir. "Sonuç olarak Türkiye Türkçesinde iyelik, öznelik, bildirme, zaman, tasarlama, sıfat-fiil ve zarf-fiil ekleri çok görevli eklerdendir." (Ceritoğlu, 2011, s. 1244). Mesela, -lAr biçimbirimi hem şahıs hem çokluk anlatır. Muharrem Ergin, -A durum ekinin yaklaşma ana fonksiyonuyla otuza yakın kullanılış fonksiyonunu sayar (2009, s. 233).

Sözcük ve ek birlikteliğinde, hem anlam hem şekil olarak aynı dilbilgisi kuralı geçerlidir. Bundan dolayı ekler de tıpkı sözcükler gibi yapı ve anlam penceresinden değerlendirilmelidir.

Türkçede ekler yapı olarak yalın, birleşik ve birlikte olmak üzere üç ayrı kullanım biçimine sahiptir. Eklerin etimolojisi, tarihsel kullanımı ve günümüzdeki şeklini alma süreci 1şığında hemen hemen bütün eklerin bu sinıflandırmadaki yeri tayin edilebilir. Ancak, görev olarak eklere bu kadar keskin sınırlar çizmek mümkün değildir. Yine de birtakım muğlaklıklara rağmen ekin anlam sağlama işlevine dayalı nesnel işleyişler tespit etmek ve dilin mantığını ortaya koyan bir sınıflandırma yapmak dilin bir sistem oluşunun doğal sonucudur. Türkçede sözcük-ek ilişsisi üzerinden eklerin sözcüğü başka bir sözcüğe dönüştürme veya tür/görev değiştirme ('dur-mak' isme, 'su-lu' sıfata, 'ben-ce' zarfa, 'su-la' fiile) (Gülsevin, 2004, s. 1277), sözcüğün türünü değiştirmeden genişletme (sabah-sabahleyin, klsa-kısacık, ev-evler), durum bildirme (yol-da, uzak-tır, güzel-miş) temsil ('biz-e' bizim için), türetme (uç-ak, gözde) gibi bir yanı biçimsel olan anlama dayalı bir işleyiş söz konusudur (Delice, 2000, s. 232, 233). Bunlara ilave olarak belli eklerin belli sözcük türleriyle veya belli alandaki sözcüklerle 
(renk adları, sayılar, organ adları gibi) kullanımı söz konusudur. Yine bazı eklerin tıpkı sözcükler gibi kalıplaştığı, aşındığı veya kullanımdan düştüğü gözlemlenmektedir. Bütün bu hususiyetler sınıflandırmalarda göz ardı edilemeyecek işleyişlerdir.

\section{Söz Dizimi ve Ekler}

Türkçede sözcük öbekleri ve cümle kalıpları kuruluş olarak çoğu zaman eklere dayanmaktadır. Söz dizimsel sınıflandırmalar genellikle kimi eklerin varlığı veya yokluğu üzerinden yapılmaktadır. Türkçede öbekler, kısaltma grupları ve tamlamaların çoğunda belirleyici olan kurucu eklerdir (Delice, 2000, s. 228). Kurucu ekler tamlama ve sözcük öbeği kurmada görev alan eklerdir. Öte yandan ekler, cümlenin unsurlarını tayin edici role de sahiptir. Bir cümlenin sadece ek iskeleti bile, tek başına bize cümledeki sözcüklerin türü, cümlenin ögeleri, zamanı hatta anlamı konusunda bir şeyler anlatır, bir sistemin varlığına işaret eder.

Dil, söz yığınından cümle sistemine birtakım ekler sayesinde dönüşür ve kullanım sahasına çıkar. $\mathrm{Bu}$ anlamda eklerin bağlama ve kurma işlevi vardır. " $+\{A\}$ durum biçim biriminin asıl işlevi, 'adları eylemlere bağlamak'tır. Ancak söz konusu biçim birimin 'adları ilgeçlere bağlamak' işlevi de zamanla kabul edilmiş ve dil bilgisi kitaplarında yerini almıştır. Bildirimiz boyunca tartıştığımız üçüncü işlev de 'adları adlara bağlamak'tır.” (Boz, 2008, s. 416).

Üretici-dönüşümsel dilbilgisi penceresinden baktığımızda eklemeli dillerin dolayısıyla Türkçenin sınırlı sayıda cümle, öbek veya tamlama kalıbıyla varsayımsal olarak sınırsız sayıda cümle, öbek veya tamlama üretebilme gücünün eklere dayandığını söyleyebiliriz. Belirtili isim tamlamasının kalıbını bildikten sonra bugüne kadar kurulmamış bir tamlamayla karşılaşsak bile bunu anlamakta güçlük çekmeyiz. Aynı şeyi cümle kalıpları için de söyleyebiliriz (Başkan, 2003, s. 124).

\section{Sözlükbilim ve Ekler}

Sözlükbirimleri türetmelerine rağmen yapım ekleri sözlüklerde yer almaz. Kavram oluşturma gücüne sahip olan yapım eklerinin türetme potansiyeli, eki almış sözcükler üzerinden sözlüklerde ortaya konulabilir. Burada itiraz mahiyetinde eklerin sözcük veya kavram olmadığ1, sözlüklerin dilin kavram kapasitesini gösterdiği düşünülebilir. Aslında ek ve sözcük sanıldığ1 kadar başka başka şeyler değildir. İkisi arasında birinin diğerine evrilebileceğini gösteren karşılıklı bir geçirgenlik bağı vardır. -yor şimdiki zaman eki ve -DIr bildirme eki sözcüğün eke dönüşmesine örnektir. Öte yandan bazı ekler de sözcük gibi kullanılmaktadır. "İzmlerle, c1larla, cularla, cakla cekle, mışla işim olmaz." ifadelerinde eklerin birer sözlükbirim olarak kullanıldığını görüyoruz. Yani ekler kelimeleşebilir. "Dilde ek olarak kullanılan morfolojik unsurların zaman içerisinde kelime hâline gelmesine leksikalizasyon denir. Kısaca ekin kelimeleşmesidir.” (Demirci, 2014, s. 128).

Eklerin kavrama dönüşebilme ve sözcüklerin eke dönüşebilme özelliği göstermektedir ki bu iki morfem dilin aynı yasalarına tabidir.

\section{Bürünbilim ve Ekler}

Bürünbilim, dilin bürünbirim dediğimiz ton, ezgi, vurgu, uzunluk gibi boyutlarını ele alır. Bunlar, parçalanabilir gramer yapıları olarak incelenemeyen konuşma hususiyetleridir. Bürünbirimler, söz zincirinde tek parçaya indirgenemedikleri için 'parçalar üstü yapılar' olarak tanımlanır (İmer, Kocaman, Özsoy, 2013, s. 217).

Ekler, sözcük ve anlamın bir parçası olarak bürünbilimin inceleme sahasına girer ve onun işletim yasalarına tabidir. "Sesbilimsel çerçeveye girmeyen, daha açık bir deyişle, şu ya da bu biçimde, ikinci eklemlilik dışında kalan bütün söz olgularına bürünbilimde yer verilir." (Martinet, 1998, s. 98). Türkçede anlam, eklerin farklı vurgu ve tonlanmasıyla da kontrol 
edilebilmektedir. $\mathrm{Bu}$ anlamda mesela kip ekleri ve soru eki oldukça işlevseldir. Bilmiyormuş, ifadesinde -muş'u farklı tonlayarak 'inanmama' anlamını elde edebiliriz.

Dil çalışmalarında ek ile vurgu ve tonlama ilişkisine pek yer verilmemiştir. Bu konuda tespit edebildiğimiz kadarıyla Gülsevin, ek incelemelerinde vurguyu bir kategori olarak ele alır ve vurgusuz eklere değinir (2004, s. 1271).

\section{Sonuç}

Türkçedeki yapım eki-çekim eki ayırımı genel, sınırları iyi tayin edilmemiş ve eksik bir sınıflandırmadır. Dilbilgisinin her bir alt alanında bile birçok kullanım farklılığı sergileyen ekleri iki temel ayırıma tabi tutmak çok sığ bir değerlendirme olur. Ekler, ses bilim, biçim bilim, söz dizimi, sözlükbilim ve bürünbilim alanlarında farklı görünümlere sahiptir. Sınıflandırma çalışmalarının bu görünümlerin kural ve işleyişlerine dayanması gerekir.

Ses bilim kuralları eklerin yapı ve işleyişi için de geçerlidir. Eklerin ses birimleri ve bunların birleşim özellikleri, ses bilimin inceleme alanına girer.

Birer biçimbirim olmaları dolayısıyla ekler, sözcüklerle aynı kurallara tabidir. Sözcüklerin yapı ve işlev özelliklerini eklerde de aramak gerekir. Sözcüklerin yapı ve tür sınıflandırmasında esas alınan kriterlerle benzer bir ek sınıflandırması yapılabilir.

Sözcük öbeği, tamlama ve cümlelerin söz dizimsel yapısı çoğu zaman eklerle kurulur. Türkçe gibi eklemeli dillerde dilin bir sistem oluşu ek veya ek işlevine dayanır.

Ekler sözlükbirimlere, sözlükbirimler de eklere dönüşebilmektedir. Sözlük bünyesinde Sözlükbirimlerin oluşturduğu sözcük aileleri gibi eklerin de özellikle yapım eklerinin ilişkili oldukları sözcüklerden oluşan aileleri vardır.

Ek ve bürünbilim ilişkisi daha çok vurguya dayalıdır. Türkçede çekim ekleri genellikle vurgusuz, yapım ekleri vurguludur. Böylece ekler vurgu özelliklerine göre vurgulu ekler ve vurgusuz ekler olmak üzere ikiye ayrılmaktadır.

Eklerin dilbilimin alt alanlarındaki kullanımlarının irdelenmesi, sınıflandırma çalışmalarında esas alınabilecek kriterlerin belirlenmesine katkıda bulunacaktır.

\section{Kaynakça:}

Başdaş, Cahit (2006), “Türkçede Üçüncü Grup (Ara) Ekler”, I. Uluslararası Büyük Türk Dili Kurultayı, 26-27 Eylül 2006, Ankara.

Başkan, Özcan (2003), Lengüistik Metodu, Multılıngual, İstanbul.

Boz, Erdoğan (2008), “+\{A $\}$ Durum Biçim Birimi (Söz Dizimsel Bir İşlev Olarak) Adları Adlara Bağlayabilir mi?", Türk Dili Dil ve Edebiyat Dergisi, C. XCV, S. 677, Ankara, s. 410417.

Ceritoğlu, Murat (2011), "Türkiye Türkçesindeki Çok Görevli Eklerin Tespiti ve Sınıflandırması", Gaziantep Üniversitesi Sosyal Bilimler Dergisi, C. 10, S. 3, s. 1239-1248.

Delice, H. İbrahim (2000), "Türk Dilinde İşlevsel Ek Tasnifi Denemesi”, Cumhuriyet Üniv. Sosyal Bilimler Dergisi, S. 24, Sivas, s. 221-235.

Ergin, Muharrem (2009), Türk Dil Bilgisi, Bayrak Yayınları, İstanbul.

Gülsevin, Gürer (2004), “Türkçede 'Sıra Dışı' Ekler ve Eklerin Tasnif-Tanımlanma Sorunu Üzerine”, V. Uluslararası Türk Dili Kurultayı Bildirileri I, TDK Yayınları, Ankara, s. 12671284.

İmer, Kâmile, Ahmet Kocaman, A. Sumru Özsoy (2013), Dilbilim Sözlüğ̈̈, BÜTEK, İstanbul. Karaca, Hasan (2013), Türkiye Türkçesinde Eklerin Işslevleri, Basılmamış Doktora Tezi, (Cumhuriyet Üniversitesi, Sosyal Bilimler Enstitüsü), Sivas.

Martinet, Andre, (1998), İşlevsel Genel Dilbilim, (Çev. Berke Vardar), Multılıngual. 
Özel, Ali (2003), Türkçede Eklerin Tasnifi, Basılmamış Yüksek Lisans Tezi, (Cumhuriyet Üniversitesi, Sosyal Bilimler Enstitüsü), Sivas.

Turan, Zikri (2000), "Türkçenin Yapım ve Çekim Düzeninde Yer Alan Eklerin Sinıflandırılması Nasıl Olmalıdır?”, 4. Uluslararası Türk Dil Kurultayl, 25-29 Eylül 2000, İzmir.

Vardar, Berke (2002), Açıklamalı Dilbilim Terimleri Sözlüğü, Multilingual, İstanbul 